\title{
Стихотворение Юному поэту и новелла Моцарт В. Я. Брюсова сквозь призму некоторых философских концептов Фридриха Ницше
}

\section{The Poem To a Young Poet and the Novella Mozart by Valery Bryusov through the Prism of Some Nietzsche's Philosophical Concepts}

\section{Патрик Варга}

(Оломоуц, Чешская Республика)

\begin{abstract}
:
The article introduces the interpretation of the two Valery Bryusov's works-the poem To a Young Poet and the novel Mozart from the perspective of the chosen Nietzsche's philosophical concepts. It aims at the examination of the problem to what extent Valery Brjusov is, being directly or indirectly influenced by Nietzsche's thinking, constant in his works. The article also provides the interpretation of the transformation of Bryusov's thinking, which is, to a certain extent, conditioned by the conception of the world and its aesthetics according to the first generation of symbolists in Russia. The author comes to the conclusion that Valery Bryusov is coincident with the aesthetic conception of Nietzsche's philosophy so typical of French modernism. However, using irony, Bryusov is able to point out particular Nietzsche's requirements on the reader which were, for the majority of people, impossible to meet.
\end{abstract}

Key words:

Valery Bryusov; Friedrich Nietzsche; the Übermensch; Russian symbolism; Mozart 
Предлагаемая вниманию читателей статья ставит своей целью интерпретацию и сравнение стихотворения «Юному поэту» (1896) [BRJUSOV 1896] и новеллы «Моцарт» (1915) [BRJUSOV 1915] Валерия Яковлевича Брюсова с точки зрения важнейших концептов ницшеанской философии (аполлоновское и дионисийкое начала в искусстве, сверхчеловек и существо, стоящее по ту сторону добра и зла). Характер данной интерпретации заключается не столько в выявлении генетического влияния на В. Брюсова ницшевской мысли, т. е. не в поисках прямых, «материальных» доказательств использования Валерием Яковлевичем идей $\Phi$. Ницше в процессе создания текстов, сколько в раскрытии присутствия в них некоторых оригинально модифицированных В. Брюсовым черт духа времени Серебряного века, насквозь пропитанного интеллектуальной обработкой идей немецкого мыслителя. Для контраста были выбраны тексты, промежуток времени между годами создания которых составляет почти 20 лет, т. е. бо́льшую часть золотой эпохи российской ницшеаны.

Посредством анализа и сравнения двух вышеупомянутых брюсовских текстов будет рассмотрен вопрос, ставящий себе целью установить, насколько В.Брюсов менял свои воззрения и отношение к Ф.Ницше, или насколько он неизменно придерживался в силу своего восхищения французскими символистами, ценивших в Ф.Ницше «гениального эстета, имморалиста, разрушителя эстетических идеалов» [SINEOKAJA 2001, 17] и воспринимавших сверхчеловечество как достижение точки абсолютной свободы человека-творца, создателя собственной морали и мира именно эстетического восприятия Ницше. Данную теоретическую подоплеку вопроса можно отчасти продемонстрировать и с помощью мысли чешского слависта Яна Ворела, следующим образом охарактеризовавшего эстетичско-философское развитие В. Брюсова:

„Je ovšem nutné uvědomit si, že Brjusov, i když se ve svém myšlenkovém a uměleckém vývoji postupem času odklání od krajního subjektivizmu svých raných básnických a esejistických děl, nikdy nepřijal Merežkovského myšlenku o směřování umění $\mathrm{k}$ mystické a náboženské jednotě. Skutečným náboženstvím pro něho vždy zůstalo právě umění samo o sobě, které se stává životem a život, který se stává uměním jako cesta k překonání veškerého zla." [VOREL 2012, 174].

Еще одной отправной точкой для следующих размышлений полужил тезис А. Лаврова, утверждающего, что «тематически-образные структуры развиваются зачастую в прозе и поэзии Брюсова паралелльно» [LAVROV 1989, 7]. Данное положение относится в высказывании А. Лаврова к текстам, возникавшим на одних и тех же этапах брюсовского творчества. Одной из частных целей 
настоящей статьи будет являться попытка выявить, не существуют ли такие, хотя бы модифицированные и не полностью соответствующие друг другу, паралелли и в текстах, более друг от друга отдаленных во времени.

На рубеже XIX и XX веков трудно представить себе в Европе интеллектуальную среду, так или иначе не воспринявшую идей Ф. Ницше. Будучи верным своим собственным словам, он стал динамитом, взорвавшим традиционное миропонимание многих мыслящих людей. В силу своего громкого призыва переоценить все ценности, Ф.Ницше представляет собой по сути коренной пересмотр развития европейской культуры в самом широком смысле (религия, искусство, наука и т. д.). Им же были затронуты и потрясены самые ее основы, неприкосновенные ранее аксиомы.

Среди старших русских символистов он получил огромную популярность прежде всего благодаря своему подчеркиванию эстетической сущности мира и утверждениям о ведущей роли искусства и художника в познании и созидании жизни. Символистское ожидание грядущего времени, в котором искусство станет жизнью и жизнь искусством, жизнетворчество способствовало рецепции и модификациям ницшевской философии в данном круге деятелей искусств. Новую жизнь, нового человека должно было создать новое искусство, далекое от социальных задач реализма, тем более натурализма, преобразовывающее своего реципиента изнутри [DEPPERMANN 1992, 228-229].

Мышление $Ф$.Ницше со своей установкой на переоценку ценностей, на будущее, на разрушение старого, со своим апофеозом искусства (музыки) и философией, обращенной к конкретному индивидууму и возможностям его преобразования изнутри, соответствовало настроенному на интеракцию горизонту ожиданий части русской интеллигенции рубежа веков (постницшевское христианство, модернизм), при этом оно подверглось в ходе его интерпретации существенным модификациям, обусловленным специфичностью русского интеллектуального ландшафта и большим разбросом целеустановок отдельных философских направлений. Но вне сомнения остается тот факт, что мышление Фридриха Ницше послужило мощным толчком для активизации творческих сил России рубежа веков, которой в свое время не могло быть равных.

Сравнение тематических планов в стихотворении «Юному поэту» и новелле «Моцарт» является с моей точки зрения подтверждением мыслей Ю. Синеокой и Я.Ворела, усматривающих в брюсовских произведениях обработку эстетических взглядов французских и старших русских символистов. Однако, с точки зрения отношения рассказчика / лирического субъекта к тематическому плану произведений можно указать на некоторые отличия между текстом стихотворения и текстом новеллы. Главной отличительной чертой 
в данном случае я считаю долю иронии, с которой относятся лирический субъект в «Юному поэту» и рассказчик в новелле «Моцарт» к «героям» этих текстов. В то время как в первом случае допустимо говорить об искренности обращения лирического субъекта к не состоявшемуся еще поэту и стремлении закрепить за стихотворной формой заветов идейную программу старшего русского символизма, в другом случае приходится говорить о явно ироничном отношении рассказчика к Латыгину. Он специально подбирает такие моменты и обстоятельства из жизни главного героя, которые указывают на несостоятельность латыгинского убеждения в собственном превосходстве над другими и силе своего искусства (любовница Маша - жалкое существо, свои новейшие композиции герою приходится играть на кухне при участии всего лишь дочери и жены, прозвище Моцарт, присужденное ему в насмешку от соседей и т. д.).

Следует отметить, что любой из интерпретируемых концептов ницшевской мысли носит характер пересечения двух направлений мышления, на которые обращает внимание В. Кауфманн, утверждая, что:

„Nietzsche ist, wie Plato, kein Systemdenker, sondern ein Problemdenker. [...] In der Problemsituation sind Voraussetzungen enthalten, und durch die Untersuchung werden einige ausdrücklich gemacht. Das schließliche Ergebnis ist nicht so sehr eine Lösung des anfänglichen Problems, als vielmehr die Einsicht in seine Grenzen: das Problem wird in der Regel nicht gelöst, man wächst über es hinaus." [KAUFMANN 1988, 96].

Следовательно, Ф. Ницше стремится не столько до конца проследить логическую цепь предпосылок, образующих проблему, и таким образом ее решить, сколько находить возможности, благодаря которым ее можно перерасти, забраться на ступеньку выше ее. Существенным здесь безусловно является метафорически выраженное направление мысли и жизни не просто дальше, а ввысь (Lebenssteigerung).

Вторым важным ницшевским принципом является провозглашенная Ф. Ницше неразрывная связь философии с жизнью. Каждая философская проблема должна стать личной, экзистенциальной проблемой философа, а не частью отвлеченной сферы сугубо умственных занятий.

„Dadurch, daß Nietzsche jedes Problem ,durchlebt', erkennt er Konsequenzen, die von den nichtexistenziellen Denkern - die die Probleme nur historisch behandeln - übersehen worden sind." [KAUFMANN 1988, 107]. 
Настоящий принцип идеально вписывается в ницшевскую идею философии жизни (Lebensphilosophie), основывающейся на вышеупомянутых призывах к интеллектуальной честности / вечному экспериментированию и предполагающей первенство вечно движущейся и меняющейся жизни перед любой законченной системой, т. е. способность мыслящего человека к адаптированию своего мышления в зависимости от жизненных обстоятельств.

„Nietzsche beharrt darauf, dass ein Philosoph gewillt sein muss, immer wieder neue Versuche zu unternehemen; [...] allerdings schwebte ihm (Nietzsche) die fröhliche Wissenschaft des furchtlosen Experimentierens vor Augen, die Bereitschaft, wo nötig, neue Ansichten anzuerkennen und frühere Postionen zu verwerfen." [KAUFMANN 1988, 101].

Человек должен стать согласно Ф.Ницше новым творцом - создателем мира, жизни. Таким образом, мы подходим к следующему важному как для модернизма в целом, так и для нашей интерпретации моменту: апофеозу искусства в мышлении Ф.Ницше. Оно же понимается им как ключ к сути мира, т.е. как главное средство познания.

Необходимо упомянуть еще два аспекта философии Ф. Ницше. Речь идет о типичном для модернизма повороте интереса интеллектуального и художественного дискурса от человечества к человеку, т. е. о фокусировании не на отношениях человек - общество, а на внутреннем мире индивидуума, в идеальном случае, совершенно автономного существа. Такое существо, потерявшее жизненные ориентиры в качестве божества, моральные установки, веру в смысл существования, не может увильнуть от конфронтации с тем, что я предлагаю называть обобщенно: эмансипацией тьмы, домогающейся права на сосуществование с привилегированным в сознании европейского человека светом.

По мнению Ю.Синеокой, в центре внимания «российской ницшеаны» находится концепт сверхчеловека. Она обращает внимание на размытость данного концепта, у которого нет (и быть не может) единой дефиниции сверхчеловека, что способствовало возникновению широкой интерпретационной гаммы (В. Соловьев, Д. Мережковский, А. Скрябин и т. д.). Для старших русских символистов стали закономерно важными стороны сверхчеловечества, касающиеся творческой потенции и ее использования в целях создания нового, совершенного существа [SINEOKAJA 2001, 17].

Тескт и рассказчик новеллы «Моцарт» вступает в косвенный диалог с текстом и лирическим субъектом стихотворения «Юному поэту», в рамках которого можно наглядно показать не только обработку тем, затронутых уже в «Юному 
поэту», но и тот факт, что Брюсов продолжал обрабатывать свои взгляды на искусство и его миссию, включая их ницшевские элементы, на протяжении всей своей творческой жизни. В «Моцарте» он пародирует фигуру мнимого гения, гения-неудачника, подчеркивая таким образом символистскую склонность к элитарности (гений как избранник) и важность и требовательность безукоризненного соблюдения заветов, выдвинутых, в частности, в «Юному поэту» (чтобы дать врожденной гениальности расцвести). Брюсовский рассказчик в новелле с большой долей иронии доказывает, что не каждый способен заниматься творчеством на поприще модернистских деятелей искусства.

Личность главного героя данной новеллы, скрипача Латыгина, построена по принципу противоречий. Какого из его жизненных мотивов ни коснись, он всегда предстает перед читателем в виде человека, находящегося между двух огней. Примечательно, что, желая быть гением, настоящим декадентом, перешедшим полностью из пренебрегаемого им обыденного мира в мир искусства, где жизнь и искусство нераздельно сливаются, он постоянно возвращается назад. Он не может стать абсолютно свободной личностью и окончательно перешагнуть моральный порог мира по ту сторону добра и зла, совершить сверхчеловеческий идеал Ницше, заключающийся по мнению Р. Сафранского в полном, т. е. тотальном развитии возможностей человека «das Vollbild des Menschenmöglichen» [SAFRANSKI 2013, 280]. Если придерживаться такой точки зрения, то Латыгин - несостоявшийся сверхчеловек. Каждая его попытка нацелить развитие своей жизни вверх (с точки зрения декадентства) заканчивается неудачей.

Первый завет в стихотворении «Юному поэту», содержащем канон поведения молодого декадента, запрещает жить настоящим, т.е. обыденным, повседневной суетой. Взор поэта должен быть устремлен в будущее, которое он помогает создавать - безоговорочная установка на будущее (стремление к новому типу человека и т. д.) является одной из основных черт ницшевской философи. С первой заповедью очень тесно связана заповедь вторая, запрещающая любое проявление сочувствия другим.

Поэт должен придерживаться строго индивидуалистического подхода к жизни, создавая только свое будущее, свою жизнь. Он же представляет собой посланника мира искусства в обыденном, реальном мире, нуждающийся ради достижения своей миссии в абсолютной свободе личности. Каждое отношение к другому человеку уже является ограничением абсолютной свободы.

Третий завет подытоживает два предыдущих - устремленная в будущее и абсолютно свободная творческая личность (идеал сверхчеловека в понимани французских символистов и многих русских старших символистов, включая Брюсова) может и должна всецело служить искусству. 
Латыгин считает себя Моцартом, гением, заслуживающим жить в блеске культурных столиц, в то время как его окружение подтрунивает над «Моцартом», живущим незамеченным в провинциальном городке. Первый из контрастов можно обнаружить уже при рассмотрении названия новеллы и его отношения к главному герою. Вольфганг Амадей Моцарт принадлежит бесспорно к числу тех, кого европейская культура привыкла называть гениальными творцами. Для нас здесь важна не столько реальная историческая биография Моцарта, сколько легенда, миф, образовавшийся вокруг его жизни и творчества, их восприятие в художественной среде последовавших за ним поколений.

В русской культуре решающую роль сыграла в этом плане одна из «Маленьких трагедий» А. Пушкина - «Моцарт и Сальери». Неслучайно Брюсов использует аллюзии на этот пушкинский текст, применяя высказывание: «Ты, Моцарт, Бог, и сам того не знаешь...» к личности Латыгина. Другим полюсом, манифестирующимся аллюзией на пушкинского «Скупого рыцаря», в рамках намеченной выше дихотомии контрастов можно назвать строку, которую Латыгин тоже часто повторяет: «Ах, бедность, бедность! Как унижает сердце нам она!» Оба высказывания представляют собой части внутреннего монолога главного героя. Его жизнь как будто мечется между этими двумя крайними точками - между Моцартом и «Моцартом». Он считает себя одаренным свыше, гениальным музыкантом, наподобие Моцарта непонятым своей эпохой и стоящим под постоянной угрозой всего «среднего» - убийства Сальери.

А с другой стороны он постоянно чувствует определенную долю ответственности перед своей дочерью, как минимум, в финансовом плане. В понимании модернистов идеальный гений не должен заботиться ни о деньгах, ни о семье, об обыденной жизни, следуя заветам: не живи настоящим, поклоняйся искусству и никому не сочувствуй. А Латыгин, хотя и не приносит домой спьяну все деньги, которые он должен был принести, все-таки бо́льшую их часть не тратит. Бедность не должна унижать моцартов, она унижает лишь скупых рыцарей.

Неудачную латыгинскую попытку достойно исполнять завет, вдохновленный ницшевской концепцией сверхчеловека и касающийся абсолютной свободы творца, имеющего право отвергнуть устоявшиеся моральные ориентиры и стоять таким образом по ту сторону добра и зла, следует усматривать в его отношении к женщинам. Стремление воспринимать женщину как источник художественного вдохновения и превратить ее в некую идеальную Женщину - отвлеченное умопостроение, имеющее право на существование всего лишь до тех пор, пока его можно обожествлять, наблюдается почти у всех деятелей искусств, причисляющих себя к символистскому направлению в искусстве. Но как только идеальная Женщина теряет способность выступать 
посредником между творческой личностью и Красотой, гений должен от нее отречься. Она превращается в женщину - жену, составляющей частью той обязывающей и стягивающей вниз обыденности, которой гений должен избегать. И в этом плане Латыгин демонстрирует разрыв между желанием-стремлением и реальными возможностями своей личности.

По выше указанным причинам он не может больше любить свою жену. За исключением того момента, когда он ночью и спьяну усмотрит в ней следы былого вдохновения, вообразит ее прежней девушкой, в которую он был страстно влюблен. Тогда он сможет провести с ней ночь. Но утром все встает на свои места. Женщина с большой буквы опять стала женщиной.

Почти идентичная ситуация происходит с его любовницей Машей. Ее он заводит из-за ее некритичного обожания его таланта. Но она удовлетворяет только его самолюбие, тщеславие и природные инстинкты, что может длиться лишь недолго. Никаких следов вдохновения в тексте не обнаруживается. Последнюю долю привлекательности это отношение теряет в тот момент, когда Латыгин осознает его регулярность, т. е. предсказуемость и обыденность. Разрывая это отношение, хотя это полностью входит в канон поведения идеального гения, он проявляет сочувствие, озабоченность. Он хочет на миг вернуться к Маше, что свидетельствует об еще одном глубочайшем разрыве между идеалом и реальностью латыгинской жизни, которая никак не может стать искусством и наоборот.

Ближе всех к идеалу Женщины несомненно стоит Ада. С первого взгляда она кажется типичной роковой женщиной. Стройная фигура, темные волосы и глаза, сочетание красного и черного цветов, ребячество и женственность, нежность и страсть. Они знакомятся вдалеке от повседневности, на теплом, полного цветов и запахов юге. Она - обладательница говорящего имени Ад + а. Ад, как и все демоническое, для модернистов-гениев гораздо привлекательнее неба, как указывает изложение причин эмансипации тьмы. В этом смысле можно утверждать, что Ада противопоставляется Маше - чистой, и для декадента-демона рубежа веков не очень интересной Деве Марии. Композитор и Ада проводят несколько вдохновенных недель в отдельном, созданном ими мире - потемневшем гостиничном номере, занавешенном красными шторами.

Первая мировая война прерывает эти отношения, однако, кажется, что источник вдохновения, открытый роковой женщиной, не иссыхает, а лишь трансформируется, поднимая латыгинское вдохновение до пока неизведанных высот. Начинается переписка, которая в первый и последний раз приближает Латыгина к идеалу слияния жизни с искусством. Он, в отличие от Ады, воспринимает данную переписку как роман, над которым он работает вместе с ней. 
Жизнь выступает здесь в служебном положении по отношению к искусству. Латыгин чувствует себя выше ей, с пером в руке он волен преобразовывать, творить ее. Небезынтересно здесь вспомнить личный опыт Брюсова в связи с его небескорыстным романом с Ниной Петровской, послужившем ему им самим управляемым вдохновением для создания «Огненного ангела» [ZADRAŽILOVÁ 1997, 403].

Итак, Латыгин упражняется в умении Lebensgestaltung и жизнь превращается одновременно в материал для искусства. Ада, соответственно, теряет свой статус роковой женщины, которая должна всегда вырывать мужчину-творца из обыденной жизни путем или его абсолютного вдохновения, или полного уничтожения, в тот момент, когда решается приехать к Латыгину и осуществить все то, о чем они переписывались в реальности. Такое превращение Женщины в женщину Латыгин уже не в силах перенести. Он окончательно (в рамках текста) осознает безысходность своего положения и, лишившись последней надежды на гениальность Моцарта и плачет вместе с эфиром, которого он волею судьбы и своего характера никогда не смог достичь.

Связующим звеном, позволяющим одновременно и объединить все три типа латыгинских отношений к женщинам (жена, Маша, Ада), и наглядно показать пародийный характер брюсовского героя-несостаявшегося сверхчеловека, являются попытки без ограничения манипулировать отдельными жизнями этих женщин, безнаказанно их подчинять себе, вершиной чего можно считать «жизнетворческий» эпизод переписки Латыгина с Адой, так как здесь речь идет уже не об икусстве в качестве убежища от жизни (жена), коротковременно приятным способом вызвать к себе обожествление (Маша), а чистой попыткой перековать жизнь (в том числе чужую) на предмет искусство, не смотря на возможный ущерб другого. Каждая из латыгинских попыток в даном отношении заканчивается неудачей, подчеркнутой ироническим тоном в голосе рассказчика.

Еще одним очень важным аспектом ницшевского наследства нужно считать ориентацию русских (и старших и младших) символистов на концепт аполлоновского и дионисийского начал в искусстве и с ними связанную господствующую позицию музыки в системе искусств и восприятия жизни. Музыка является самым приближенным к бесконечному, трагическому, дионисийскому началу бытия видом искусства. Она оказывается посредником при соприкосновении с ним, но одновременно и спасает благодаря своей отчасти аполлоновской форме от полного растворения по-дионисийки настроенного реципиента в экзистенциальной бездне. По Ф. Ницше, музыка является самым приближенным к бесконечному, трагическому, дионисийскому началу бытия видом искусства. Она оказывается посредником при соприкосновении 
с ним, но одновременно и спасает благодаря своей отчасти аполлоновской форме от полного растворения по-дионисийки настроенного реципиента в экзистенциальной бездне.

„Behutsam ist gerade das Element, als unapollinisch, ferngehalten, das den Charakter der dionysischen Musik und damit der Musik überhaupt ausmacht, die erschütternde Gewalt des Tones, der einheitliche Strom des Melos und die durchaus unvergleichliche Welt der Harmonie. Im dionysischen Dithyrambus wird der Mensch zur höchsten Steigerung aller seiner symbolischen Fähigkeiten gereizt; etwas Nieempfundenes drängt sich zur Aeusserung, die Vernichtung des Schleiers der Maja, das Einssein als Genius der Gattung, ja der Natur." [NIETZSCHE 2012, 24].

Ключ к иррациональной, не до конца понятной сущности космоса, ее лучшая, осознаваемая человеком манифестация, ведущая к окончательному слиянию всех мнимо существующих отдельно явлений в нераздельный дифирамбический вселенский хор, к бесконечности - Музыка, переполненная экстатическим, растворяющим ограниченную личность человека в вечности дионисийским началом при маленькой доле аполлоновского. В этом заключается суть ницшевского понимания Музыки.

Старший русский символизм, унаследовав в известной степени эти взгляды и от романтиков и актуализировав их под воздействием идей Ницше, поставил именно Музыку во главу иерархии искусств. Композитору и скрипачу Латыгину удается коснуться такой Музыки с большой буквы в рамках новеллы лишь два раза. Первый такой момент мы обнаруживаем в тексте в сцене за завтраком, когда дочка просит музыканта сыграть ее любимую композицию латыгинскую Колыбельную. Но Латыгин отказывает дочери в ее желании в предвкушении собственного погружения в мир Музыки и ошеломляющего успеха после прозвучания его новой композиции - Танца медуз. Желание дочери должно уступить искусству (поклоняйся только искусству + никому не сочувствуй). Старое пусть останется позади, гений смотрит только в будущее, создает новое (не живи настоящим).

Здесь наглядно использован принцип Lebenssteigerung и метод постоянного экспериментирования. Рассказчик переносит нас вовнутрь латыгинских представлений, образов и ассоциаций, представляющих собой эстетский апофеоз Красоты как высшей ценности, как ценности самой по себе. Красота - те изысканные, в вышей степени эстетические движения медуз, которые видны во тьме глубокого океана, традиционного символа бесконечности, только за счет их собственного, изнутри льющегося света. В музыке он ищет спасения 
в качестве окончательного слияния с космической гармонией - «Evangelium der Weltenharmonie» [NIETZSCHE 2012, 21].

Но еще до полного растворения индивидуальности в бесконечности Латыгина возвращает назад в обыденное его жена, играющая в этом смысле с его точки зрения роль опасного для гения Сальери - на данный момент олицетворения всего среднего, к которому он, как бы он ни старался, прочно привязан (в том числе и через дочь). Латыгин вынужден отправиться на работу, где его ожидает соприкосновение с искаженной музыкой в виде унизительного преподавания уроков скрипки непонятливой, бесталанной ученице. «Моцарт» горбится ради денег перед мещанкой, чего мифический Моцарт, т. е. идеальный гений сделать не может (поклоняйся только искусству).

Второй раз Латыгину удается погрузиться в Музыку во время гастролей на Черном море. Здесь можно опять продемонстрировать с помощью одного «суб-контраста» роль брюсовской иронии в данной новелле, так как идеальный гений, представление о котором складывалось в европейской культуре долгие века, ищет своего вдохновения на Юге, т.е. либо в Италии, либо в Греции (дочерью которой является как раз Ада) - наследницах духа античности. А Латыгину предоставлена лишь возможность попутешествовать по югу тогдашней Российской империи, он гастролирует в Одессе. Тем не менее он упивается своим успехом, наслаждается на миг творческой свободой, пестрой жизнью порта и неозадаченностью с точки зрения повседневности. Именно в Одессе он знакомится с Адой, гречанкой несвязанной больше с Грецией, заводя с ней бурные, вдохновляющие отношения, как и подобает идеальному гению. Здесь жена-Сальери уже не в силах вернуть его назад в обыденность, но, тем не менее, появляются другие, более сильные форсмажорные обстоятельства, заставившие Латыгина вернуться - упомянутая уже выше Первая мировая война. Не он, как сверхчеловек, побеждает ее, т. е. какие бы то ни были внешние обстоятельства, а она побеждает его - карикатуру сверчеловека.

В очередной раз он не может пересечь границу в сверхчеловеческий мир, соблюсти заповеди, предназначенные в брюсовском стихотворении «Юному поэту» грядущим деятелям нового искусства, раствориться в дионисийском элементе музыки и окончательно превратить жизнь в искусство, искусство в жизнь и таким образом совершить действие, обрамленное контурами рассмотренных выше ницшевских принципов в восприятии старшего русского символизма. В прозаической форме здесь выражено восклицание лирического субъекта, созданного В. Брюсовым в 1895 г. в стихотворении «Мучительный дар»: «Земля мне чужда / небеса недоступны // Мечты навсегда / навсегда невозможны. // Мои упованья пред миром преступны / Мои вдохновенья пред небом ничтожны!» [BRJUSOV 1895] 
В заключение можно сказать, что брюсовские произведения «Юному поэту» и «Моцарт» представляют собой примеры обыгрывания разных граней миросозерцания деятелей искусств эпохи модернизма, в котором восприятие мышления Ф.Ницше сыграло решающую роль. В творчестве старшего поколения русских символистов преобладала склонность к эстетическому толкованию ницшевской мысли, что сказывается, по-моему, не только в «Юному поэту», но и в сюжете новеллы «Моцарт». Оба произведения взаимосвязаны с тематической точки зрения, однако, доля иронии лирического субъекта и рассказчика по отношению к объекту их внимания разная. В Моцарте она играет несоменно решающую роль при обличении героя в карикатурности, в пародии на сверхчеловека, в то время как в более раннем брюсовском стихотворении является с моей точки зрения вопросом дискуссионным.

Валерий Брюсов представил в своем стихотворении тип гениального творца сверхчеловеческого толка как возможную реальность, в то время как в Латыгине как реальную невозможность.

\section{Библиография:}

BRJUSOV, V. (1896): funomu poètu. <http://az.lib.ru/b/brjusow_w_j/text_oo4o.shtml>. [online]. [cit. 28. 6. 2018].

BRJUSOV,V. (1915): Mocart. <http://az.lib.ru/b/brjusow_w_j/text_o150.shtml>. [online]. [cit. 28. 6. 2018].

BRJUSOV, V. (1895): Mučitel'nyj dar.<http://az.lib.ru/b/brjusow_w_j/text_oo4o.shtml>. [online]. [cit. 28. 6. 2018].

DEPPERMANN, M. (1992): Nietzsche in Russland. In: EMDEN, Ch. J., HEIT, H., LEMM, V., ZITTEL, C., ABEL, G., STEGMAIER, W. (Hrsg.): Nietzsche-Studien. Bd. 21. Berlin-Boston, s. 211-252.

KAUFMANN, W. (1988): Nietzsche. Philosoph, Psychologe, Antichrist. Darmstadt.

LAVROV, A. (1989): Proza poèta. In: NIKONENKO, S. (ed.): V. Ja. Brjusov. Izbrannaja proza. Moskva, s. 5-20.

NIETZSCHE, F. (2012): Gesammelte Werke. Köln.

SAFRANSKI, R. (2013): Nietzsche. Biographie seines Denkens. Frankfurt am Main.

SINEOKAJA, Ju. (2001): Rossijskaja nicšeana. In: SINEOKAJA, Ju. (ed.): Nicše: Pro et contra. Sankt-Peterburg, s. 2-29.

VOREL, J. (2012): Od dekadence k teurgii. Esteticko-filozofická hledání české a ruské literatury prelomu 19. a 2o. století. Ostrava.

ZADRAŽILOVÁ, M. (1997): Umělecká projekce životního př́běhu. In: BRJUSOV, V.: Ohnivý anděl. Praha, s. 399-415. 
Př́spěvek vznikl za podpory MŠMT, grant IGA_FF_2016_o44 Text a intertextualita ve slovanských literaturách a kultuře.

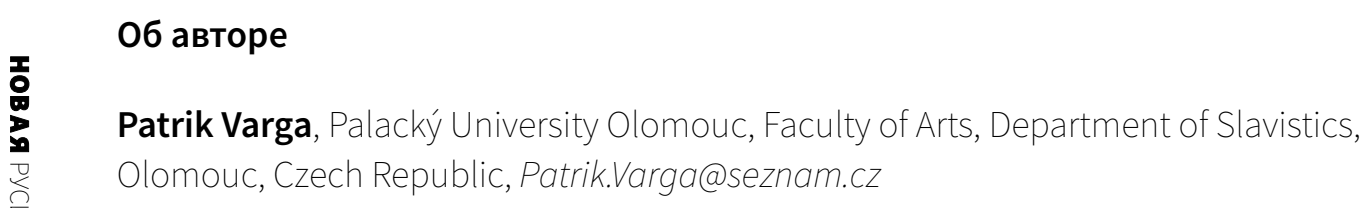


